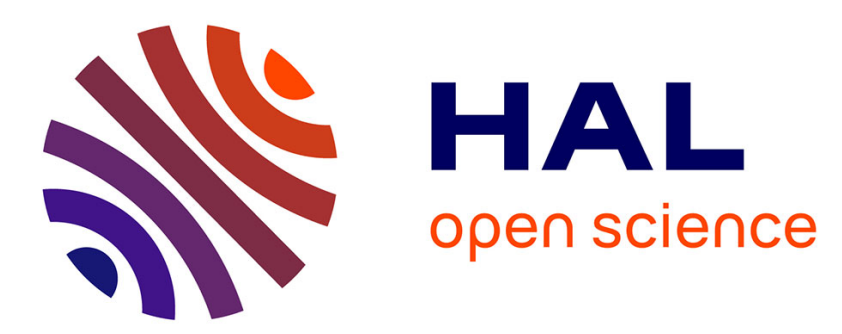

\title{
The first ROBAFIS-ROBSE international student competition in Systems Engineering
}

\author{
Jean-Claude Tucoulou, Eric Bonjour, David Gouyon
}

\section{To cite this version:}

Jean-Claude Tucoulou, Eric Bonjour, David Gouyon. The first ROBAFIS-ROBSE international student competition in Systems Engineering. INSIGHT - International Council on Systems Engineering (INCOSE), 2017, 20 (4), pp.45-46. 10.1002/inst.12181 . hal-01666762

\section{HAL Id: hal-01666762 https://hal.science/hal-01666762}

Submitted on 18 Dec 2017

HAL is a multi-disciplinary open access archive for the deposit and dissemination of scientific research documents, whether they are published or not. The documents may come from teaching and research institutions in France or abroad, or from public or private research centers.
L'archive ouverte pluridisciplinaire HAL, est destinée au dépôt et à la diffusion de documents scientifiques de niveau recherche, publiés ou non, émanant des établissements d'enseignement et de recherche français ou étrangers, des laboratoires publics ou privés. 


\section{The first international student competition in Systems Engineering}

By Jean-Claude Tucoulou (jc.tucoulou@afis.fr), Eric Bonjour (eric.bonjour@univ-lorraine.fr), David Gouyon (david.gouyon@univ-lorraine.fr).

The authors would like to thanks especially Sven-Olaf Schulze, Claudio Zuccaro, Hanno Weber and Jan Zutter, organizers of the reception of this event in Deutschland.

French and German students in Systems Engineering (Master degree in Complex Systems Engineering of the University of Lorraine in Nancy, and Master degree in Systems Engineering of the Applied Sciences University of Munich) were taking part to an international challenge, since October 2016, to design, assemble and validate a robot with an approach of Systems Engineering. The same requirements document had been proposed by AFIS and GfSE (French and German chapters of INCOSE) to the competitors and the competition meeting was planned in March 2017.

The development files written by each team have been judged of very good quality. The meeting with a phase of operational validation and a friendly confrontation was planned in Pforzheim in Germany. The French team from Nancy had taken part in the edition "RobAFIS 2016" and the German team had taken part in the edition "RobSE 2016/2017".

The robot was designed to ensure three successive and different missions with a phase in autonomous mode, then a phase in teleoperation mode. The missions consisted in depositing a beacon on a black rectangle, then two beacons on black rounds, then three beacons on black squares. The tele operation was carried out with a " blind " manner, thanks to a embarked video channel of a camera received and displayed on the control center.

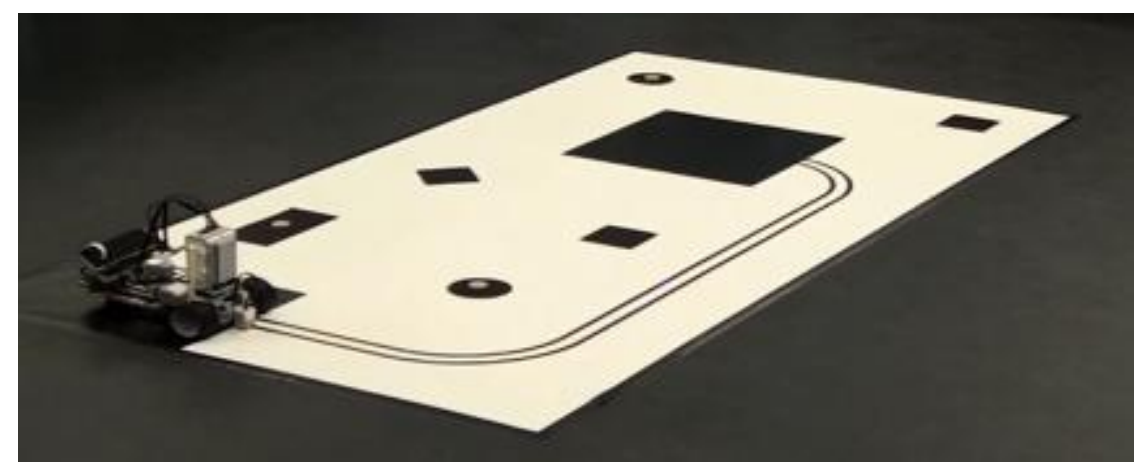


Operational environment for the 3 missions.

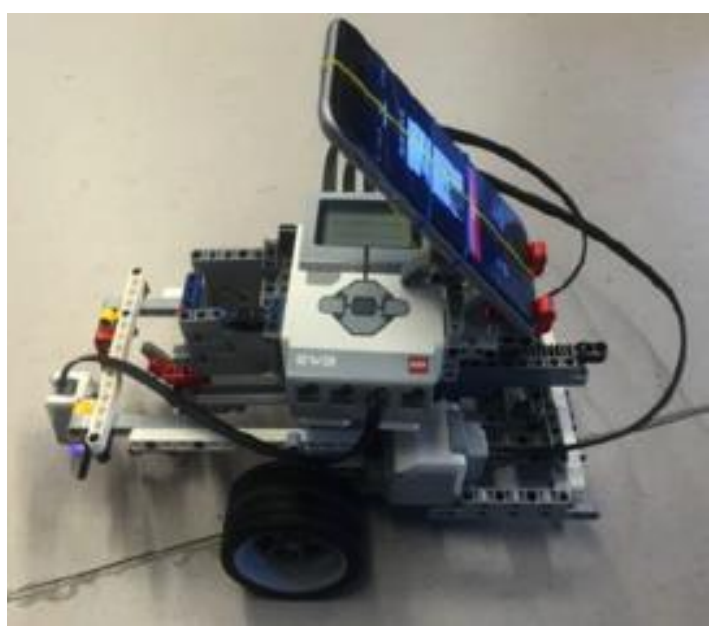

Robot built by the German team

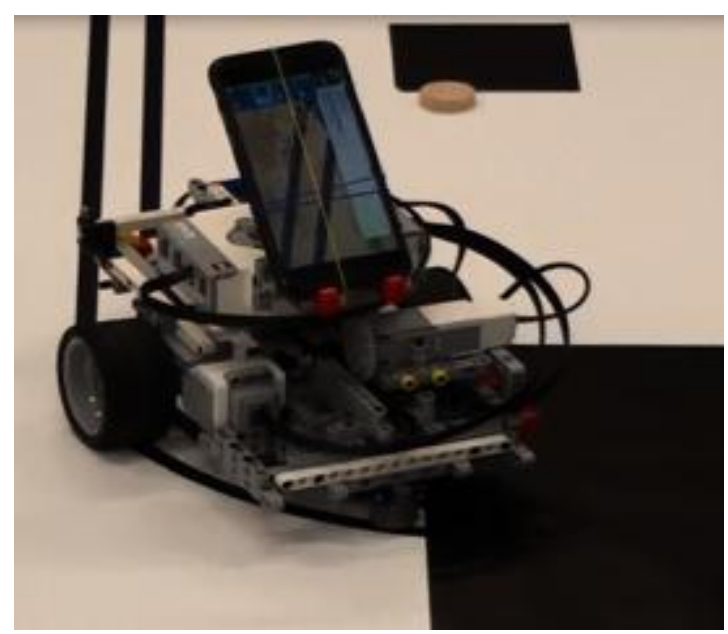

Robot after the deposit of a beacon

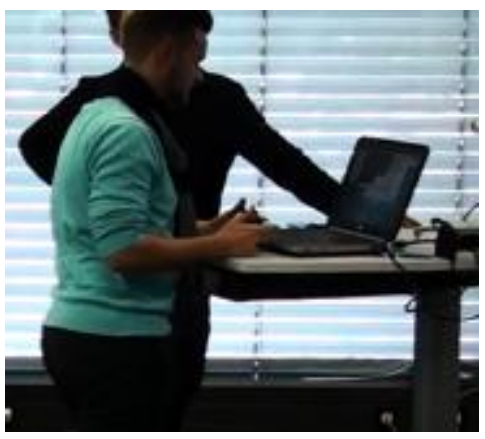

Teleoperator 


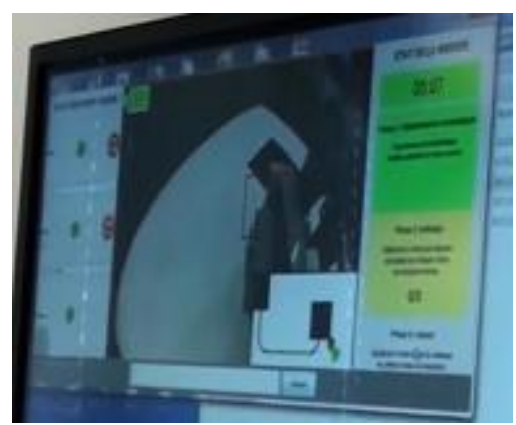

Control center

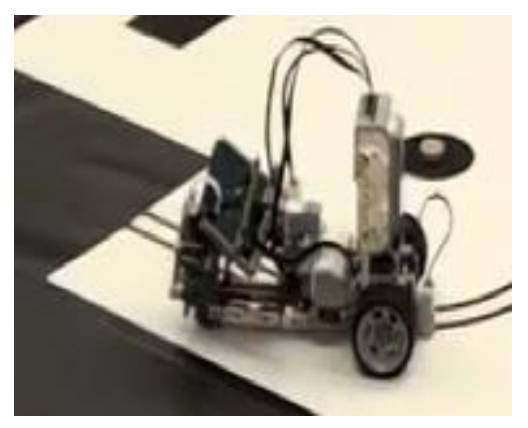

Robot in autonomous mode (Nancy - France)

The RobAFIS competition has been organized in France for 11 years and driven by the operations manager Jean-Claude Tucoulou. About ten student teams of universities and schools of engineers meet each year (24 establishments have already taken part to this competition since its creation). Considering that this competition is successfully organized, the German chapter of INCOSE (GfSE) created, with the support of AFIS, the RobSE competition in 2016 to place this teaching challenge (with the principle of learning systems engineering by project) at the disposal of the German establishments of higher education.

On February 3rd, 2017, the first international student competition in SE took place within the establishment of higher education of Pforzheim, located geographically halfway between Munich and Nancy. Let us thank from now Professor Dr. Hanno Weber for his warm welcome and the perfect organization of this day.

A jury has evaluated: (1) the development files prepared by the two teams, (2) the oral defense of their project by each team and (3) the operational evaluations of the mission performed by the robot of each team.

Concerning the development files judged of very good quality, it arises two slightly different approaches of design. The students of the master degree of the University of Lorraine have had a comprehensive approach on the basis of the system and of its environment to seek solutions for each subsystem, by specifying the interfaces, before their assembly and verification. The students in Systems Engineering coming from the higher establishment of Munich have designed the subsystems progressively by integrating them gradually and by starting with the most critical subsystem, ensuring the displacement of the robot. 
The numerous questions of the jury were related to, for example, the choices of architectures, the specifications of the interfaces, the allocations of requirements to the subsystems or to the activities of Verification and Validation of the adopted solution. The two teams explained and argued their choices of the design and the organization of their project. The jury could feel all the motivation and the enthusiasm of both the German and French students which was for their professors first great satisfaction!

The quality of the development files has to be put in comparison with the quality of the operational tests.

The performance of the missions was very efficient for the two teams, Nancy succeeding in collecting 38 points/45 and Munich performing nearly without fault with $42 / 45$, showing the very high level of this competition.

After the evaluation of the various phases of the competition, and considering that they did not succeed in choosing the best performance between the two teams, the jury decided to declare the two teams as being ex aequo and winners of the competition RobAFIS-RobSE 2017 and strongly congratulated them for the high quality of their work.

The second objective of this day was to bring together professors coming from the University of Lorraine (Nancy), Dr Eric Levrat, Dr David Gouyon, from the University of Munich, Dr Claudio Zuccaro, from the University of Pforzheim, Dr Hanno Weber, as well as the vice-president Teaching - Research of AFIS, Dr Eric Bonjour from the University of Lorraine, and in the presence of the President of the German chapter of INCOSE (GfSE), Sven-Olaf Schulze.

They thus could exchange on their practices of the training of systems engineering and planned to develop possible co-operations. The INCOSE EMEA workshop in Mannheim, Germany, in September 2017 (the workshop is, at the time when these lines are written, a future event), is the opportunity for them to continue their exchanges.

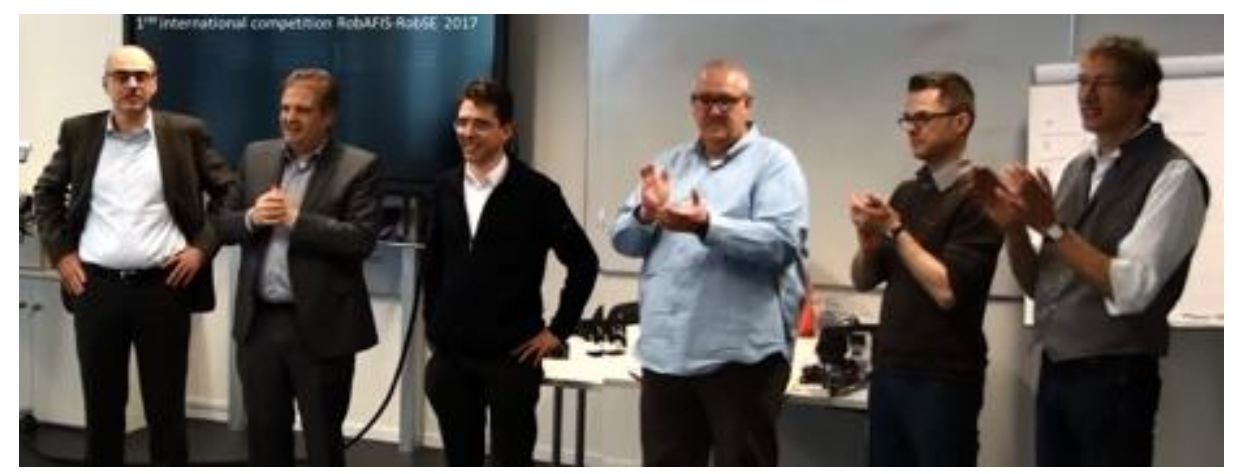

Sven-Olaf Schulze and Eric Bonjour closed this day by thanking again the University of Pforzheim and Jean-Claude Tucoulou, Vice-president of AFIS and operations manager of RobAFIS, whose great involvement and long experience of the RobAFIS competition made the organization of this international competition possible. 